\title{
Simulation and Analysis of Function Damage Effect for Typical Mechanical Transmission System
}

\author{
Cai Chen ${ }^{1,}$, Q Quan Shi ${ }^{1}$, Guangyan Wang ${ }^{1}$, Qiang Wang ${ }^{1}$, Bangjun Chen² \\ ${ }^{1}$ Ordnance Engineering College, Shijiazhuang, Hebei, 050003, P.R. China; \\ ${ }^{2}$ Troop of 78616, Chengdu, Sichuan, 610214, China. \\ acaichen20091165@126.com
}

\begin{abstract}
By studying gear meshing force variation law, the function damage effect of involute gear transmission system under the situation of the structural damage can be obtained. It can provide the basis for the quantitative evaluation of function damage effect for gear transmission system. A computation method based on dynamic simulation is proposed. Through establishing the 3D model of broken gear and using the dynamic simulation software ADAMS to establish the dynamic model of involute gear transmission system based on the Hertz contact theory. Then the simulation analysis is carried for different broken length of the tooth and different load. The simulation results show that broken tooth and load both will influence the meshing force, and the influence law is different when the broken length or the load is different.
\end{abstract}

Keywords: Gear meshing; Tooth broken; Simulation; ADAMS

\section{Introduction}

With the research of equipment damage law more and more deeply, traditional equipment damage evaluation from the angle of structure damage cannot adapt to the demand of modern high-tech war. Especially for modern machinery equipment, the trend is moving in the direction of large-scale, high-speed, continuous and automated. The structure damage will cause a chain reaction, which can cause the function damage of corresponding device. As a typical mechanical drive system, gear transmission system has an important influence on the performance of the gear transmission system. And in the gear transmission system, the involute gear is one of the most widely used type. Through studying the law of gear meshing force changes in the battle, the performance of gear transmission system can be evaluated quantitatively. In previous studies, it only considered the regularity of gear meshing force in the normal situation, but not considered situation in the battle [1-6]. Therefore, there is a need to analyze the variation law of meshing force in the battle situation.

Because the amplitude of meshing force is large and gears are always in rotary motion state, the meshing force is difficult to be measured. In this paper, the virtual prototype model of gear transmission system is established, and the variation law of meshing force under different load is analyzed by using the multi-body dynamics simulation technology. This research lays the foundation of quantitative evaluation of function damage for gear transmission system.

\section{Fundamental Theory}

\subsection{Determine Parameters of Contact Force}

There are two methods to calculate the contact force in ADAMS. One is the compensation method, and another is impact function method. Normally, the impact function is used to solve the contact force between the two components. It divides the contact force into two parts. One is elastic force and another is damping force. The function is [7]:

$$
F=K x^{e}+F_{s}(x, 0,0, d, C) \dot{x},
$$

where $K$ is the meshing stiffness; $x$ is the penetration depth between two components; e is the nonlinear index; $F_{s}$ is the step function; $d$ is the maximum allowable penetration depth between 
components; $C$ is the maximum damping coefficient; $\dot{x}$ is the mutual penetration rate of two components.

In the Eq. (1), the value of the nonlinear index for metal material is 1.5. It reflects the degree of nonlinear of the materials. The damping index $\mathrm{C}$ is often set as $0.1 \%-1 \%$ of stiffness coefficient and it reflects the collision energy losses. The maximum penetration depth $\mathrm{d}$ is generally taken as $0.1 \mathrm{~mm}$.

From Eq. (1), it can be known that the meshing force $F$ has relation with gear meshing stiffness, contact deformation, the nonlinear index, damping coefficient, and the penetration depth.

The gear meshing stiffness $K$ can be determined by the follow formula [8]:

$K=\frac{4}{3} R^{1 / 2} E^{*}$

Where $R$ is synthetic curvature radius; $E^{*}$ is integrated elasticity modulus.

$$
E^{*}=\frac{E_{1} E_{2}}{E_{1}\left(1-v_{2}^{2}\right)+E_{2}\left(1-v_{1}^{2}\right)}
$$

Where $v_{1}$ and $v_{2}$ represent material Poisson ratio of two gears respectively; $E_{1}$ and $E_{2}$ represent the elastic modulus of materials respectively.

$$
R=\frac{R_{1} R_{2}}{R_{1}+R_{2}}
$$

where $R_{1}$ and $R_{2}$ represent equivalent radius of curvature for two contacted point respectively.

The calculation method of curvature $R$ for spur gear is shown as bellow [9]:

For a pair of meshing spur gear, the radius of curvature at the node of the two tooth profile respectively is:

$$
\left\{\begin{array}{l}
\rho_{1}=\frac{d_{1}^{\prime} \sin \alpha^{\prime}}{2} \\
\rho_{2}=\frac{d_{2}^{\prime} \sin \alpha}{2}
\end{array}\right.
$$

The expression of the synthetic curvature radius is:

$$
\frac{1}{\rho}=\frac{\rho_{2}+\rho_{1}}{\rho_{1} \rho_{2}}=\frac{2\left(\frac{\rho_{2}}{\rho_{1}}+1\right)}{d_{1}^{\prime} \sin \alpha^{\prime}\left(\frac{\rho_{2}}{\rho_{1}}\right)}
$$

And

$d_{1}^{\prime}=d_{1} \frac{\cos \alpha}{\cos \alpha^{\prime}}$

$\frac{\rho_{2}}{\rho_{1}}=\frac{d_{2}^{\prime}}{d_{1}^{\prime}}=\frac{d_{2}}{d_{1}}=\frac{z_{2}}{z_{1}}=u$

Put Eq. (7) and Eq. (8) into Eq. (6), get:

$\frac{1}{\rho}=\frac{2}{d_{1} \cos \alpha \tan \alpha^{\prime}} \cdot \frac{u+1}{u}$

From Eq. (5)-(9), $d_{1}$ and $d_{2}$ are dividing circle diameters; $d_{1}^{\prime}$ and $d_{2}^{\prime}$ are pitch radius; $\alpha$ is end face meshing angle; $\alpha$ is pressure angle of end face graduated circle; $z_{1}$ and $z_{2}$ are the number of two gear's teeth; $u$ is transmission ratio.

Put Eq. (9) into Eq.(2), the stiffness coefficient of spur gear can be obtained:

$$
\begin{aligned}
K= & \frac{4}{3}\left[\frac{u d_{1} \cos \alpha \tan \alpha}{2(1+u)}\right]^{\frac{1}{2}} . \\
& \left(\frac{1-v_{1}^{2}}{E_{1}}+\frac{1-v_{2}^{2}}{E_{2}}\right)^{-1}
\end{aligned}
$$




\subsection{Coincidence Degree of the Gear}

Coincidence degree is an important evaluation index of gear's drive continuous and load transfer uniformity. The coincidence degree $\varepsilon$ is defined as follows [10]:

$$
\varepsilon=\frac{l}{p} \geq 1
$$

$l_{\text {is actual meshing length, }} p$ is base pitch of the gear. The value of coincidence degree is greater than or equal to 1 .

When the coincidence degree is higher, the more tooth are meshing at the same time and the time that a couple of tooth meshing is longer. So the load on the each tooth is smaller and the bearing capacity of the gear is greatly improved.

The following formula can be used to calculate the coincidence degree:

$$
\begin{aligned}
& \varepsilon=\frac{1}{2 \pi}\left[z_{1}\left(\tan \alpha_{a 1}-\tan \alpha^{\prime}\right)+z_{2}\left(\tan \alpha_{a 2}-\tan \alpha^{\prime}\right)\right] \\
& \alpha_{a 1}=\arccos \frac{r_{b 1}}{r_{a 1}} \\
& \alpha_{a 2}=\arccos \frac{r_{b 2}}{r_{a 2}}
\end{aligned}
$$

$\alpha^{\prime}$ is pressure angle of gear pitch circle, $\alpha_{a}$ is pressure angle of addendum circle, $r_{a}$ is the radius of addendum circle, $r_{b}$ is the radius of base circle.

\section{Establish Solid Model}

Taking a certain type of gear box as an example, the virtual prototype model of the gear transmission system is established. The internal transmission principle of the gear box is shown in figure 1 , in which the gear 1 is the load gear, and the gear 4 is the active gear.

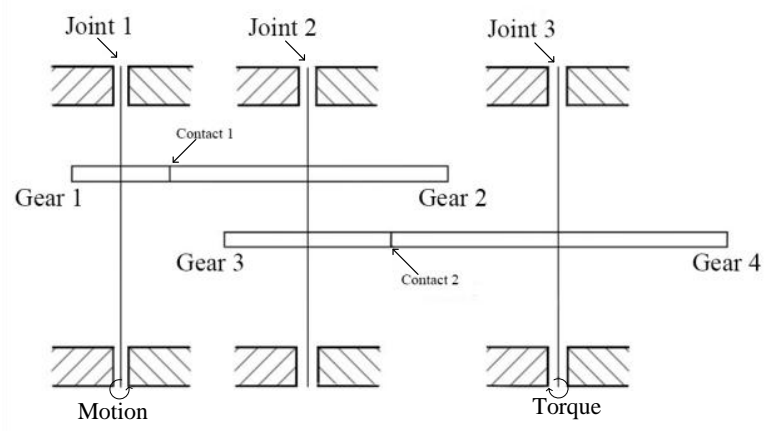

Fig.1 Schematic of transmission system

Using the powerful function of parametric modeling of Pro/E, the solid model of gear transmission system is constructed. Then the information of solid model is injected in the dynamics simulation software ADAMS. To determine the relative location of parts and eliminate the freedom of rigid body, many constraints and motions are used to connect them. As shown in figure 2, rotations are added at the barycenter of each gear. The rotation driving is added at the barycenter of gear 4 . The load torque is added at the barycenter of gear 1 . The contact force 1 is added between the gear 1 and gear2, and the contact force 2 is added between the gear 3 and gear 4 . The virtual prototype model of gear box is constructed as shown in figure 2 . 


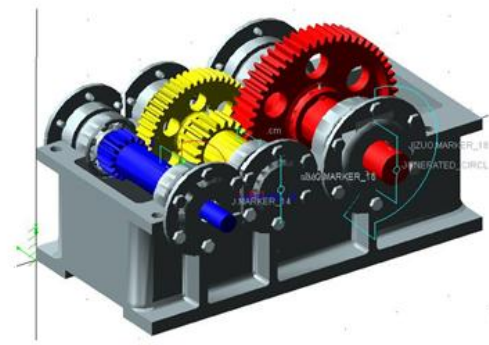

(a) Solid model of gear box

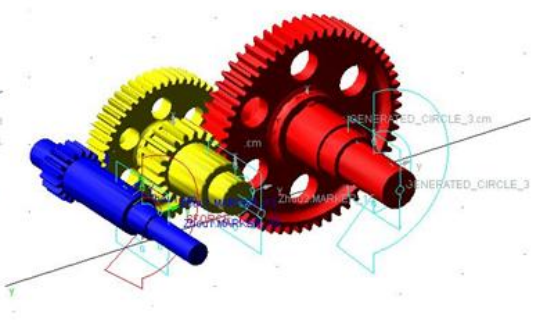

(b) Solid model of transmission system

Fig.2 Solid model of transmission system

\section{Simulation Results And Analysis}

\subsection{Determination of Parameters}

Take contact force 3 which is between the gear 3 and gear 4 as research object. The tooth number is 19 to gear 3 and 56 to gear 4 . The Poisson ratio of the material is $v_{1}=v_{2}=0.29$, and the modulus of elasticity is $E_{1}=E_{2}=2.07 \times 10^{5} \mathrm{~N} / \mathrm{mm}^{2}$. From the formula (10), $\mathrm{K}=5.68 \times 10^{5} \mathrm{~N} / \mathrm{mm}^{2}$.. The nonlinear index $e=2.2$, damping coefficient $\mathrm{C}=568 \mathrm{~N} \cdot \mathrm{s} / \mathrm{mm}$ and the torque of load is set as $T=1 \times 10^{5} \mathrm{Nmm}$. In order to make the simulation environment closer to the real environment, the step function is used to define the load which will let the load smoothly increasing in 2 seconds. The input speed of capstan is set as $1800 \mathrm{r} / \mathrm{min}$. The simulation time is set as $5 \mathrm{~s}$ and the step is set as 1875 . The result of angular velocity is shown in figure 3.

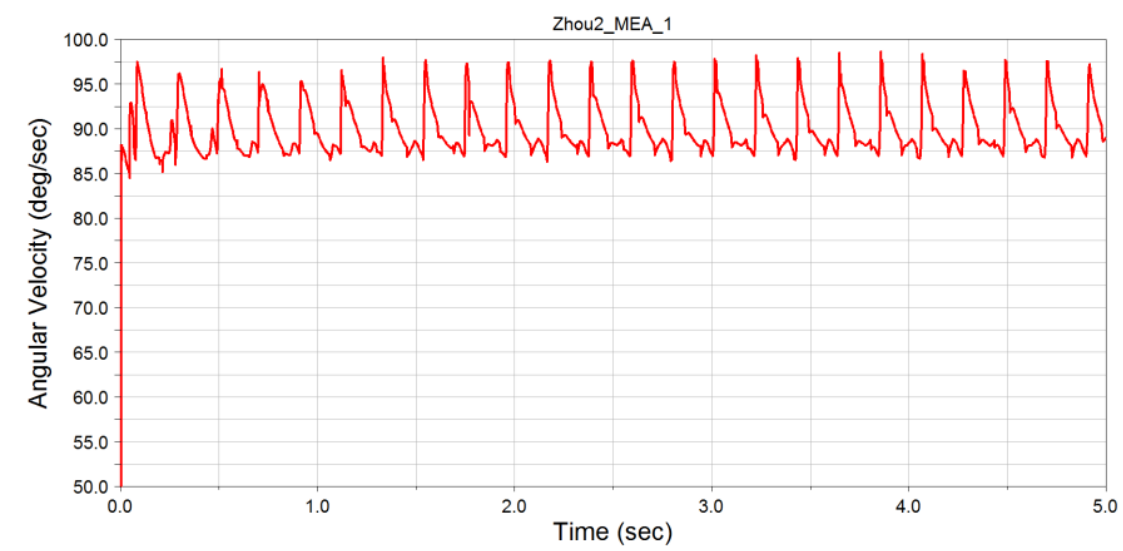

Fig.3 Angular velocity measuring curve

As shown in figure 3, the average speed of gear 2 is $89.8 \mathrm{rad} / \mathrm{s}$. So the error of simulation is $1.6 \%$ by comparing simulation value with the theoretical calculation value which is $88.4 \mathrm{rad} / \mathrm{s}$. The error meets the requirement of the experimental design and can well reflect the actual situation of the gear transmission system.

\subsection{Simulation and Analysis of Contact Force for Different Fracture Degree}

Keep rated speed and load unchanged. The change rule of meshing force under different fracture degree is simulated respectively by using gear damage simulation module which is developed independently. The change curves of meshing force of $2.6 \mathrm{~mm}, 3.5 \mathrm{~mm}, 4 \mathrm{~mm}$ and $4.5 \mathrm{~mm}$ breaking length are got respectively. The change curve from $2 \mathrm{~s}$ to $4 \mathrm{~s}$ is shown in figure 4 . 


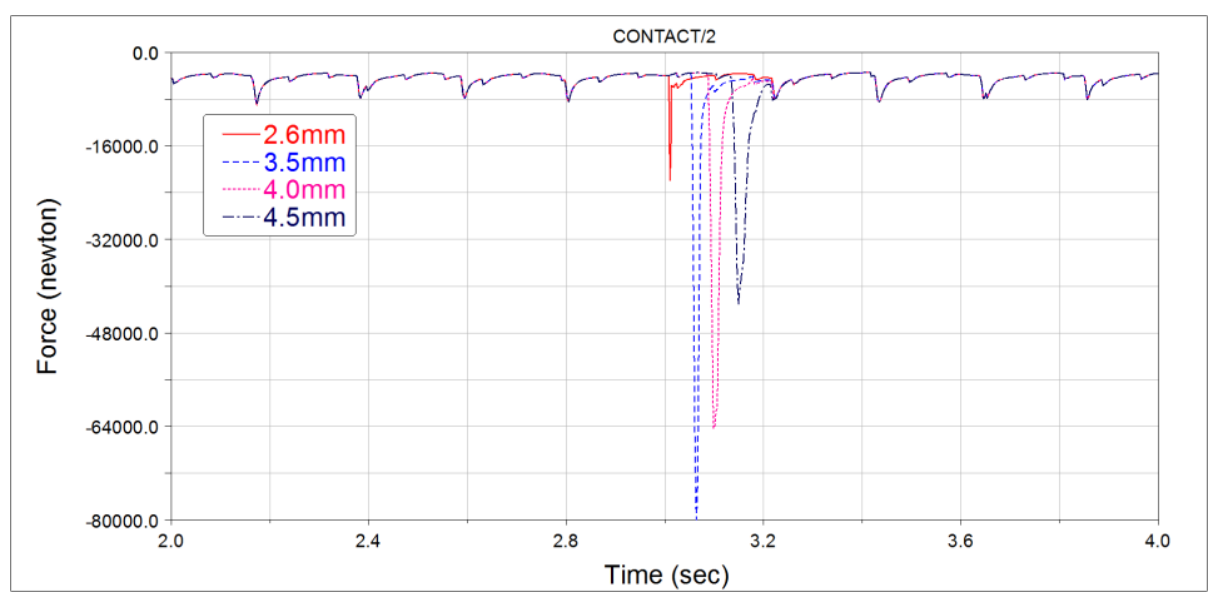

Fig.4 Tangential force measuring curve with different broken length

As shown in figure 4, when the broken tooth doesn't reach the meshing area, the meshing force has a cycle fluctuations that attach to a constant value. Fluctuation cycle and amplitude are stable cycle values which show the characteristics of gear meshing. But when the broken tooth arrives the meshing area, the meshing force is mutated, and the max value of meshing force is different for different fracture length of the gear. At the same time, with the increase of fracture length, the mutation time of meshing force is delayed gradually.

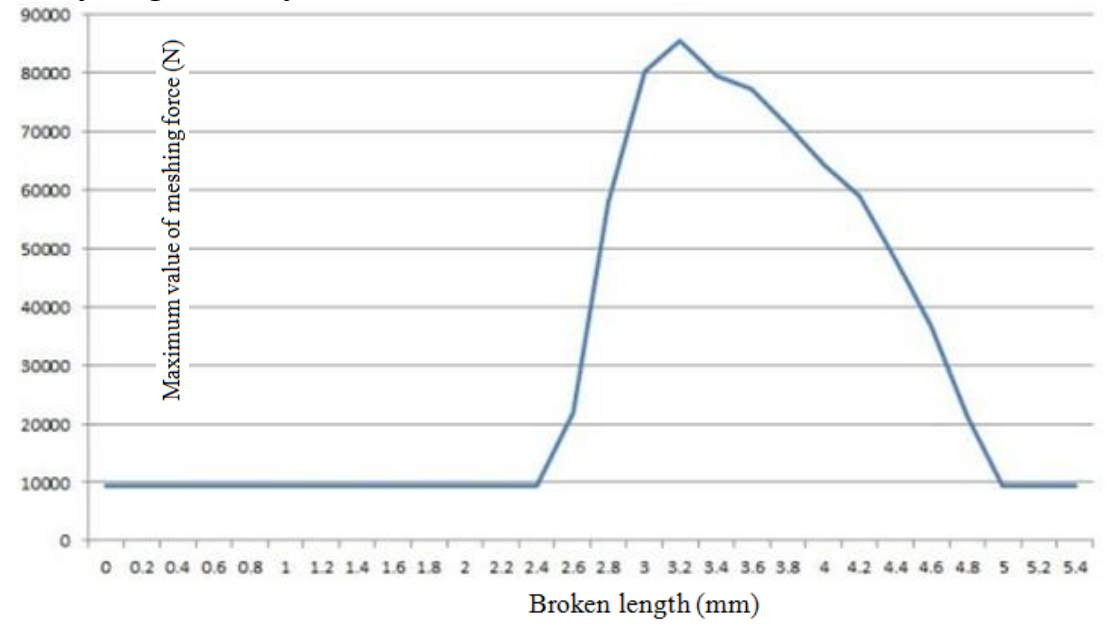

Fig.5 Maximum value of meshing force with different broken length

As shown in figure 5, the variation curves of meshing force are obtained by recording the maximum meshing force for the different fracture length. It can be seen from the figure, with the increase of fracture length, the maximum value of the meshing force does not change at first. When the fracture length reaches to $2.6 \mathrm{~mm}$, mutation of the meshing force occurs and increased with the increase of fracture length. When the fracture length is more than $3.2 \mathrm{~mm}$, the maximum value of meshing force decreased gradually. When the fracture length reached to $5 \mathrm{~mm}$, the maximum value of meshing force turns to a fixed value which is equal to the value before the mutation.

This process is mainly affected by the coincidence degree and profile characteristic of the involute gear. Because the tooth surface is cambered, the time that the broken tooth arrives the meshing area is prolonged with fracture length increases which have made the mutation time of the meshing force delay. From the concept of coincidence degree, in the process of gear turns a circle, a part of the process are two pairs of teeth engages. When the fracture length reaches to $5 \mathrm{~mm}$, the tooth no longer involves in the process of meshing. So there is no broken tooth make impact to the gear and the maximum meshing force turns to a fixed value.

\subsection{Simulation and Analysis of Contact Force under Different Loading}

Keep the rated speed constant, set the fracture length for $3.5 \mathrm{~mm}$, and respectively set the load for $50000 \mathrm{Nmm}, 100000 \mathrm{Nmm}, 150000 \mathrm{Nmm}$, and $200000 \mathrm{Nmm}$. Take simulation data of tangential force from $2 \mathrm{~s}$ to $4 \mathrm{~s}$, the result is shown in figure 6. 


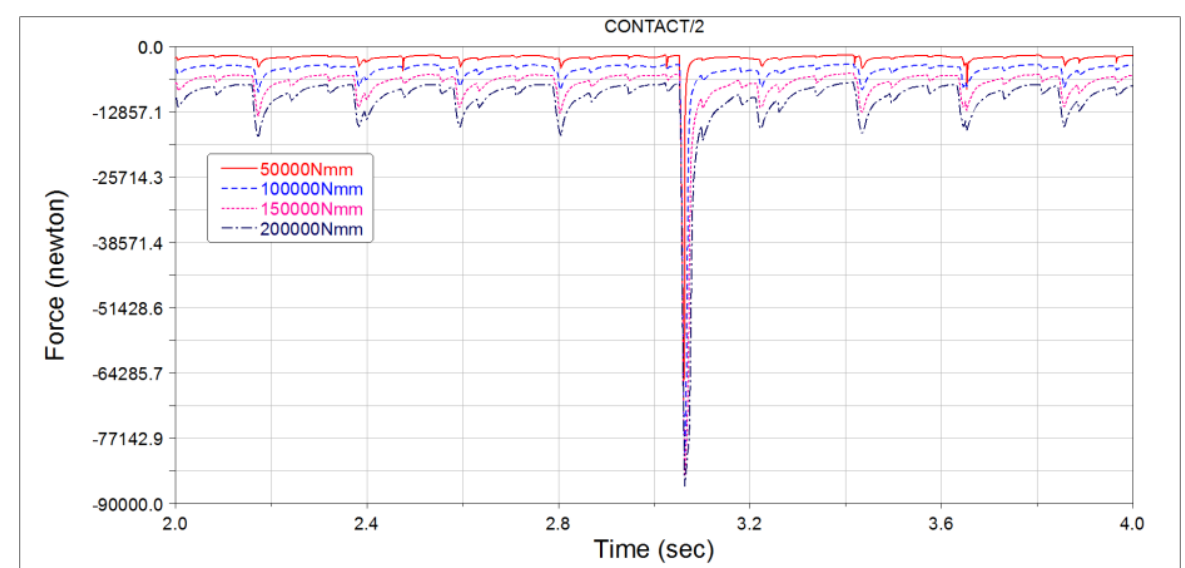

Fig.6 Tangential force measuring curve with different load

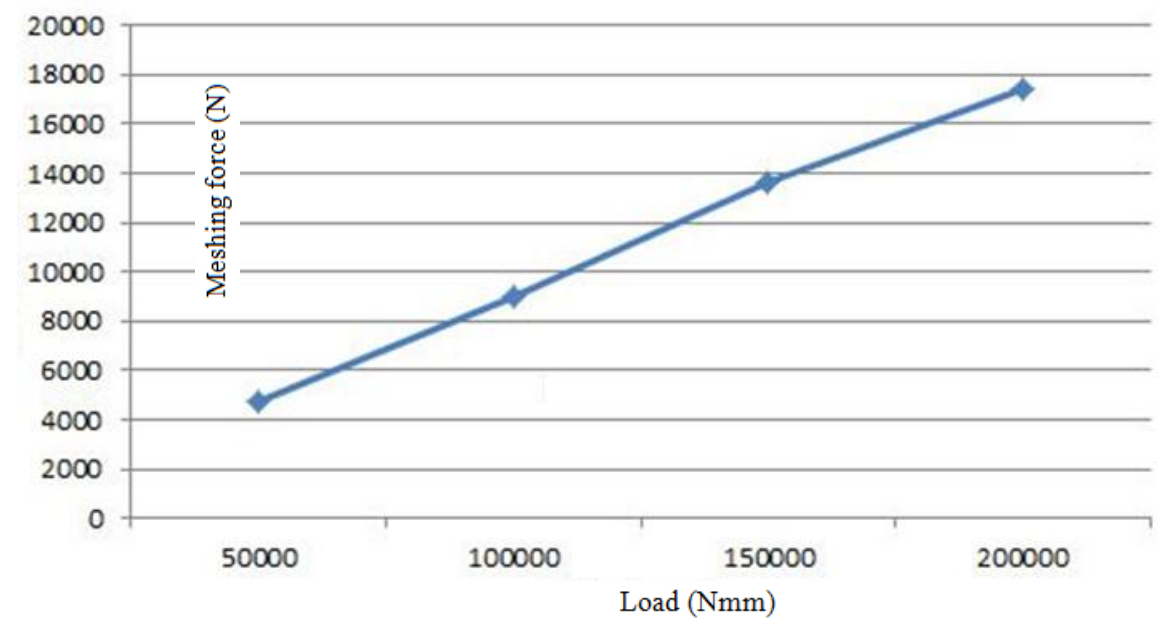

Fig.7 Meshing force measuring curve with different load in normal situation

Tab.1 The value of meshing force with different load

\begin{tabular}{cccc}
\hline $\begin{array}{c}\text { Load }(\mathrm{Nm} \\
\mathrm{m})\end{array}$ & $\begin{array}{c}\text { Maximum value of normal } \\
\text { force } \mathrm{F}_{1}(\mathrm{~N})\end{array}$ & $\begin{array}{c}\text { Maximum value of mutation } \\
\text { force } \mathrm{F}_{2}(\mathrm{~N})\end{array}$ & $\begin{array}{c}\text { Mutation } \\
\text { rate }\left(\mathrm{F}_{2} / \mathrm{F}_{1}\right)\end{array}$ \\
\hline 50000 & 4757 & 69958 & 14.71 \\
100000 & 8979 & 79920 & 8.9 \\
150000 & 13620 & 84603 & 6.21 \\
200000 & 17440 & 86534 & 4.96 \\
\hline
\end{tabular}

At the same time, the maximum meshing force for normal gear under different load conditions was recorded which were shown in figure 7 . And in the table 1, the maximum meshing force for normal gear and damage gear were respectively recorded under different load conditions.

As shown in figure 6, the meshing force remains cyclical fluctuations near a fixed value under normal condition. And the fixed value increases with the increase of the load, but the fluctuation period and the amplitude does not change. From the figure 7, it can be found that meshing force and the load has a linear relationship under normal condition. As shown in table 1, with the increase of the load, the maximum value of mutation force also increases, but the increase rate reduces gradually. It shows that with the increase of the load, its effect on the meshing force is more and more small.

\section{Conclusion}

The paper establishes the virtual prototype model of gear transmission system by using 3D modeling software Pro/E and dynamic simulation software ADAMS. And the change regularity of meshing force in different tooth fracture degree and different load has been researched. The results will not only provide some basis for battlefield damage assessment of gear transmission system, but also provide new ideas for other typical mechanical equipment battlefield damage assessment. 
However, the fracture forms of gear teeth are simplified in the case of damage injection, so the next step is to study the output error caused by the simplification.

\section{References}

[1]. Zhang Y H, Chen K, Liu X D. Dynamic Simulation Analysis of the Revolution of Secondary Reduction Gear based on ADAMS [J]. Journal of Mechanical Transmission, 2015, 39(1): 111-113, 169.

[2]. Zhao S M, Han Z N. Dynamics Analysis of Gearbox of Wind Turbine Based on Virtual Prototype Technolog[J]. Journal of Mechanical Transmission, 2013: 58-61.

[3]. Han T, Shi L, Zhao A G. Gear Fault Analysis on Wind Turbine Generator based on ADAMS[J]. Computer Aided Engineering, 2013, 22(1): 256-260, 264.

[4]. Gan J J, Wang F, Zhao M N. Design and Dynamic Simulating Analysis of Planet Gear Mechanism of Cap Screwing Machine[J]. Advanced Materials Research, 2011, 411: 3-6.

[5]. Li X, Wang Y. Analysis of Mixed Model in Gear Transmission Based on ADAMS[J]. Chinese Journal of Mechanical Engineering, 2012, 25(5): 968-973.

[6]. Guo W, Cui W M, Yang H, et al. Reliability Analysis for a Gear-Rack Based on Combination of Simulation and Experiment[J]. Journal of Donghua University(English Edition): 2015, 32(1): 144-147.

[7]. Wang L, Wu X Y. Gear Meshing Simulation Based on Virtual Prototyping Technology[J]. Mechanical Engineering \& Automation, 2013(1): 29-31.

[8]. Xu F Z, Wei X H, Zhang M, et al. Meshing Analysis of Rigid-flexible Coupled Model for Rack and Pinion Based on ADAMS[J]. Machinery Design \& Manufacture, 2012(7): 200-202.

[9]. Qiu X H, Guo K Q. Mechanical Design[M]. Beijing: Higher Education Press, 1997: 219-221.

[10]. Huang X K, Zhen W W. Mechanical Principle [M]. Beijing: Higher Education Press, 1922: 196-202 